ARTICLE

\title{
Local atomic structure modulations activate metal oxide as electrocatalyst for hydrogen evolution in acidic water
}

Yu Hang Li ${ }^{1}$, Peng Fei Liu', Lin Feng Pan ${ }^{1}$, Hai Feng Wang ${ }^{2}$, Zhen Zhong Yang ${ }^{3}$, Li Rong Zheng ${ }^{4}$, P. Hu ${ }^{2,5}$, Hui Jun Zhao ${ }^{6}$, Lin $\mathrm{Gu}^{3} \&$ Hua Gui Yang ${ }^{1}$

Modifications of local structure at atomic level could precisely and effectively tune the capacity of materials, enabling enhancement in the catalytic activity. Here we modulate the local atomic structure of a classical but inert transition metal oxide, tungsten trioxide, to be an efficient electrocatalyst for hydrogen evolution in acidic water, which has shown promise as an alternative to platinum. Structural analyses and theoretical calculations together indicate that the origin of the enhanced activity could be attributed to the tailored electronic structure by means of the local atomic structure modulations. We anticipate that suitable structure modulations might be applied on other transition metal oxides to meet the optimal thermodynamic and kinetic requirements, which may pave the way to unlock the potential of other promising candidates as cost-effective electrocatalysts for hydrogen evolution in industry.

\footnotetext{
${ }^{1}$ Key Laboratory for Ultrafine Materials of Ministry of Education, School of Materials Science and Engineering, East China University of Science and Technology, Shanghai 200237, China. ${ }^{2}$ Key Laboratory for Advanced Materials, Centre for Computational Chemistry and Research Institute of Industrial Catalysis, East China University of Science and Technology, Shanghai 200237, China. ${ }^{3}$ Institute of Physics, Beijing National Laboratory for Condensed Matter Physics, Chinese Academy of Sciences, Beijing 100190, China. ${ }^{4}$ Beijing Synchrotron Radiation Facility, Institute of High Energy Physics, Chinese Academy of Sciences, Beijing 100049, China. ${ }^{5}$ School of Chemistry and Chemical Engineering, The Queen's University of Belfast, Belfast BT9 5AG, UK. ${ }^{6}$ Centre for Clean Environment and Energy, Gold Coast Campus, Griffith University, Queensland 4222, Australia. Correspondence and requests for materials should be addressed to H.F.W. (email: hfwang@ecust.edu.cn) or to H.G.Y. (email: hgyang@ecust.edu.cn).
} 
$\mathrm{H}$ ydrogen, when generated directly from water, would be a promising chemical fuel for sustainable energy applications ${ }^{1-5}$. Development of hydrogen evolution reaction (HER), $2 \mathrm{H}^{+}+2 \mathrm{e}^{-} \rightarrow \mathrm{H}_{2}$, has attracted worldwide interest ${ }^{1,6-8}$. Platinum (Pt) can effectively catalyse the electrochemical reduction of protons in acidic media to form molecular hydrogen at low overpotentials ${ }^{9}$, which remains as the most electrocatalytically active catalyst, but its high cost and low abundance limit large-scale commercial application of electrocatalytic hydrogen evolution ${ }^{10}$. Thus, efficient Pt-free catalysts are highly desired for facilitating the global scalability of such potential clean energy technology. However, as a large and important class of chemical compounds, most transition metal oxides fail to electrocatalyse hydrogen evolution in acidic water, although numerous carbides, nitrides, phosphides and sulfides have shown the capacity for this reaction ${ }^{11-14}$.

As an important oxide, tungsten trioxide $\left(\mathrm{WO}_{3}\right)$ is much more thermodynamically stable in acidic electrolyte than most metal oxides, and it has attracted intense research interests owing to its potential applications in a wide range of fields such as catalysis, photoelectrochemical cells, photochromic devices and gas sensors $^{15-18}$. Moreover, recent reports have manifested that $\mathrm{WO}_{3}$ can act as the support of noble metals and in itself possessing electrocatalytic activity for hydrogen evolution ${ }^{19-21}$. Unfortunately, the adsorption energy of the atomic hydrogen on $\mathrm{W}$-site is undesirable, leading to the poor activity of $\mathrm{WO}_{3}$ for HER in acidic media. Noteworthy, as the descriptor of catalytic activity $^{22}$, the adsorption energies of reactive intermediates can be tuned, in principle, by tailoring the geometric and electronic structures of material, resulting in the enhancement of activity ${ }^{23}$. However, modulations of the local structure at the atomic level to tune $\mathrm{WO}_{3}$ into an active HER catalyst still remains as a great challenge.

Here we present a facile thermal treatment to activate a commercial product of $\mathrm{WO}_{3}$ into a highly competitive earth abundant catalyst, the dark blue tungsten oxide $\left(\mathrm{WO}_{2.9}\right)$, for electrocatalysing HER in acidic water (see Fig. 1 for schematic mechanism). Experimentally observed results demonstrate that the $\mathrm{WO}_{2.9}$ with tailored structure exhibits excellent HER activity with a small overpotential of $-70 \mathrm{mV}$ at the current density of $10 \mathrm{~mA} \mathrm{~cm}^{-2}$ and a Tafel slope of $50 \mathrm{mV}$ per decade. Further theoretical calculations indicate that its electrocatalytic capacity could be attributed to the modest binding energy with adsorbed

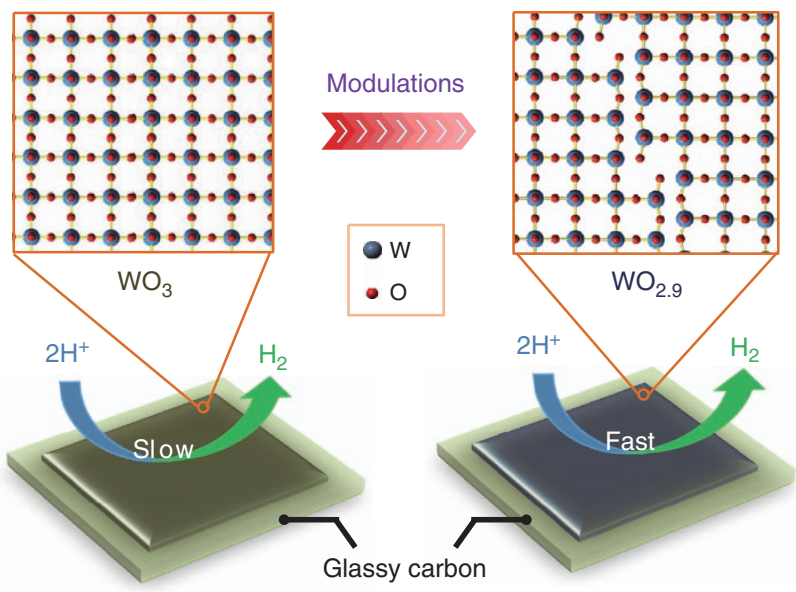

Figure 1 | Plausible reaction mechanism of electrocatalytic $\mathbf{H}_{\mathbf{2}}$ evolution. By means of local atomic structure modulations, the $\mathrm{WO}_{2.9}$ electrocatalyst with tailored electronic structure exhibits excellent HER activity, whereas the original $\mathrm{WO}_{3}$ sample is electrocatalytically inactive for proton reduction kinetics. atomic hydrogen. The findings in this work may hold the promise for the development of more practical non-Pt catalysts for electrocatalytic hydrogen evolution and other scalable technologies that harness renewable energy and convert it to $\mathrm{H}_{2}$, for example, the proton exchange membrane electrolysis in acidic environment.

\section{Results}

Electron microscopy. To prepare the $\mathrm{WO}_{2.9}$ electrocatalyst, commercially available $\mathrm{WO}_{3}$ powder was well grinded and thermally treated in a reduction atmosphere, which would readily modulate the local atomic structure of $\mathrm{WO}_{3}$ (see more details in Methods). The colour of the sample changes from light yellow (commercial product of $\mathrm{WO}_{3}$ ) to dark blue after the modifications (Supplementary Fig. 1). Scanning electron microscope (SEM) images reveal the as-prepared $\mathrm{WO}_{2.9}$ nanoparticles with a mean diameter of $100 \mathrm{~nm}$, which exhibits negligible difference comparing to the $\mathrm{WO}_{3}$ sample (Supplementary Fig. 2), indicating that the modification process in this work may not result in the aggregation of the nanoparticles. Moreover, the energy-dispersive spectrometer mapping, together with corresponding SEM image (Supplementary Fig. 3), clearly shows the existence of the elemental $\mathrm{W}$ and $\mathrm{O}$ in the $\mathrm{WO}_{2.9}$ sample. To further reveal its structure, a JEM-ARM200F scanning transmission electron microscopy (STEM) fitted with a double aberration corrector for both probe-forming and the imaging lenses is used to perform high-angle annular dark-field (HAADF) imaging. As the contrast exhibits an approximately $Z^{1.7}$ dependency for HAADF imaging, the arrangement of crystallographic structure after modification can be identified directly at the atomic scale. Figure 2 presents the HAADF images of $\mathrm{WO}_{3}$ and $\mathrm{WO}_{2.9}$ samples, where $\mathrm{W}$ atoms are clearly observed (yellow spots for $\mathrm{WO}_{3}$ and blue spots for $\mathrm{WO}_{2.9}$ ). As shown in Fig. $2 \mathrm{a}, \mathrm{WO}_{3}$ displays continuous lattice fringes with lattice spacing of 0.382 and $0.366 \mathrm{~nm}$ corresponding to the (002) and (200) atomic planes, respectively (white lines, marked as $\mathrm{A}$ and $\mathrm{B}$ ), whereas $\mathrm{WO}_{2.9}$ exhibits an extended and ordered defect structure (Magnéli phase) with a regularly stair-step shape intermittently (red lines in Fig. 2 b) ${ }^{24}$. Specifically, the bulk atomic structure of either $\mathrm{WO}_{3}$ or $\mathrm{WO}_{2.9}$ sample can also be extended to the surface, indicating the similar geometrical structure between bulk and surface (Fig. 2c,d, marked by white and red arrows). We emphasize that the surfaces and main parts of the local structures between $\mathrm{WO}_{3}$ and $\mathrm{WO}_{2.9}$ are similar, except for the stair-step shape lattice fringes in $\mathrm{WO}_{2.9}$. This suggests that the tailored electronic structure of the stair-case-shaped lattice fringes would be responsible for the enhanced HER performance of $\mathrm{WO}_{2.9}$.

X-ray analyses. In addition to the HAADF-STEM study, Fig. $2 \mathrm{e}$ displays the X-ray diffraction (XRD) pattern of the as-synthesized $\mathrm{WO}_{2.9}$ electrocatalyst. The XRD pattern of the $\mathrm{WO}_{2.9}$ sample contains an extra peak that might belong to the $\mathrm{WO}_{2.83}(-404)$ face (JCPDS Card No. 36-0103), and the other peaks are assigned well to monoclinic $\mathrm{WO}_{2.9}$ bulk (JCPDS Card No. 05-0386). On the other hand, the XRD pattern of $\mathrm{WO}_{3}$ sample illustrates the pure $\mathrm{WO}_{3}$ phase (Supplementary Fig. 4, JCPDS No. 43-1035). Besides, the characteristic peaks in Raman spectrum of the sample $\mathrm{WO}_{2.9}$ are broad and weak compared with those of sample $\mathrm{WO}_{3}$ (see details in Supplementary Fig. 5 and Supplementary Table 1), which could be attributed to the local lattice imperfections ${ }^{25}$, revealing the absence of partial $\mathrm{O}$ atoms in $\mathrm{WO}_{2.9}$ sample. Figure $2 \mathrm{f}$ reports our surface analysis for both $\mathrm{WO}_{2.9}$ and $\mathrm{WO}_{3}$ samples with the X-ray photoelectron spectroscopy (XPS) technique. For the $\mathrm{WO}_{2.9}$ sample, two major tungsten species, $\mathrm{W}^{6+} \quad\left(4 f_{7 / 2}=34.7 \mathrm{eV}\right)$ and $\mathrm{W}^{5+}$ $\left(4 f_{7 / 2}=33.3 \mathrm{eV}\right)$, are found on its surface, showing the existence 
of $\mathrm{W}^{5+}$ (ref 26). On the other hand, deconvoluted $\mathrm{W} 4 f$ doublet peaks of the $\mathrm{WO}_{3}$ sample suggest that tungsten is solely in the state of $\mathrm{W}^{6+}\left(\mathrm{W} 4 f_{7 / 2}=34.7 \mathrm{eV}\right)^{27}$. Moreover, the peaks in the XPS survey scans of the materials before and after the modulations can be only assigned to the $\mathrm{W}, \mathrm{O}$ and $\mathrm{C}$ elements (Supplementary Fig. 6), indicating the inexistence of other elements ${ }^{28}$. To know the neighbours of the $\mathrm{W}$ atoms, the $\mathrm{WO}_{2.9}$ sample was thus characterized by means of the $\mathrm{W} \mathrm{L}_{3}$-edge $\mathrm{X}$-ray absorption fine structure (XAFS). The $\mathrm{W}_{3}$-edge white line derives from electron transitions from the $2 p_{3 / 2}$ state to a vacant $5 d$ state, and Fig. $2 \mathrm{~g}$ presents the $\mathrm{W} \mathrm{L}_{3}$-edge $\mathrm{X}$-ray absorption near-edge structure spectra of the $\mathrm{WO}_{2.9}$ sample and the
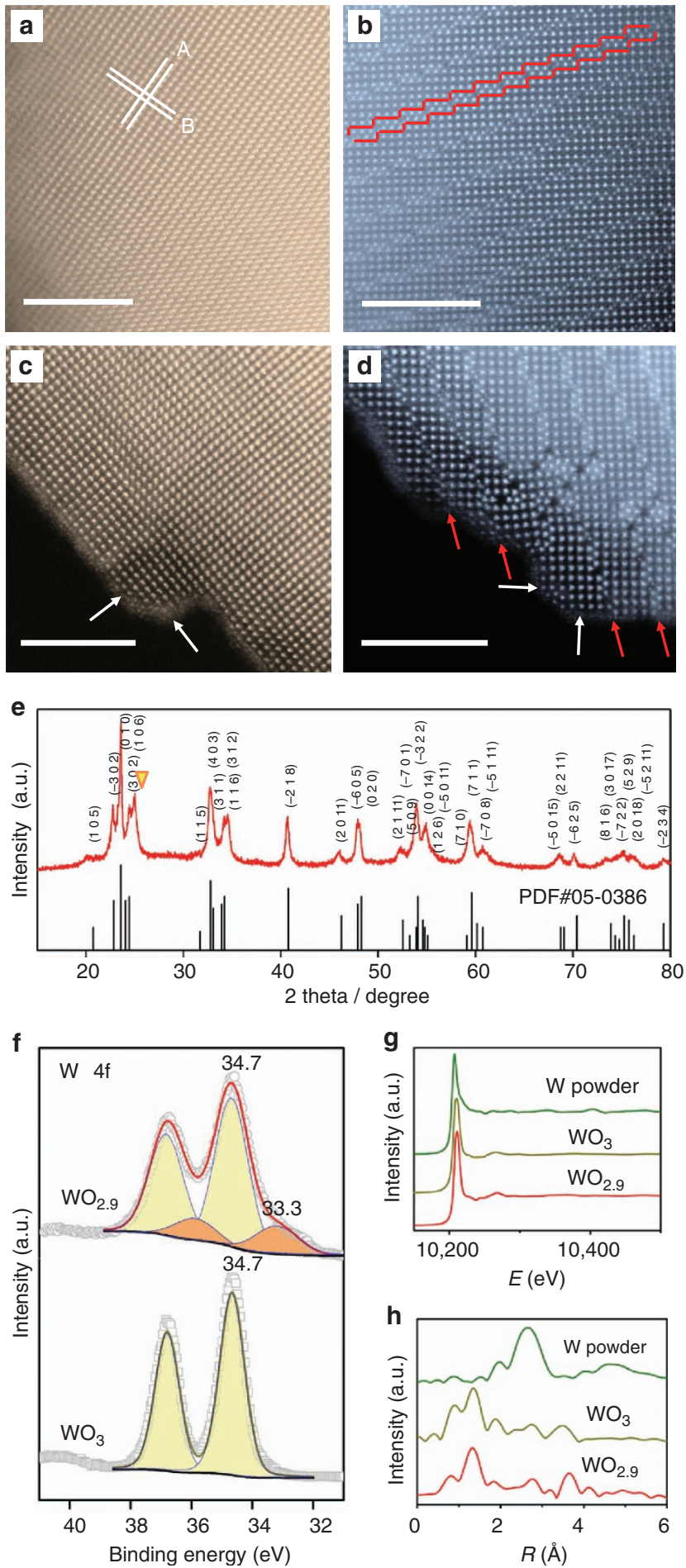

reference samples. The Fourier-transformed spectra of W $\mathrm{L}_{3}$-edge extended XAFS of the samples are shown in Fig. $2 \mathrm{~h}$. The peaks in the range $1-2 \AA$ and around $3 \AA$ appear in the curves of bulk $\mathrm{WO}_{3}$ and metallic $\mathrm{W}$ samples, respectively, owing to the $\mathrm{W}-\mathrm{O}$ shell and $\mathrm{W}-\mathrm{W}$ shell. Thus, the only peak in $\mathrm{WO}_{2.9}$ sample at $1-2 \AA$ is believed to be the contribution from $\mathrm{W}-\mathrm{O}$ binding, indicating the absence of metallic $\mathrm{W}-\mathrm{W}$ bond, which is consistent with the results of XPS W $4 f$ region that the metallic tungsten species $\left(\mathrm{W}^{0}, 4 f_{7 / 2}=30.0 \mathrm{eV}\right)$ could be hardly detected (Supplementary Fig. 7). On the basis of these results, the tungsten species in the as-synthesized catalyst could be the $\mathrm{WO}_{2.9}$ phase with only $\mathrm{W}-\mathrm{O}$ bond.

Electrochemical hydrogen evolution reaction. The electrodes for HER were prepared by drop casting a fixed volume and concentration of catalysts from an aqueous suspension onto glassy carbon disc (see more details in Methods). The HER with $\mathrm{WO}_{2.9}$ nanoparticles as the catalyst on glassy carbon electrode (GCE) was measured using a standard three-electrode electrochemical configuration in $0.5 \mathrm{M} \mathrm{H}_{2} \mathrm{SO}_{4}$ electrolyte deaerated with hydrogen. The electrodes were prepared by depositing approximately one continuous layer of $\mathrm{WO}_{2.9}$ sample over the electrode surface area. The polarization curves (not $i R$ corrected) showing the normalized current density versus voltage ( $j$ versus $\mathrm{V}$ ) for the $\mathrm{WO}_{2.9}$ catalyst along with commercial $\mathrm{Pt} / \mathrm{C}(5 \%)$ and commercial $\mathrm{WO}_{3}$ powder for comparison, are shown in Fig. 3a. Compared with blank glassy carbon, the electrode coated with bulk $\mathrm{WO}_{3}$ exhibits a poor overpotential $(\eta)$ value of $-637 \mathrm{mV}$ at the current density of $10 \mathrm{mAcm}^{-2}$, demonstrating the electrocatalytically inactive for proton reduction kinetics of the commercial $\mathrm{WO}_{3}$ powder. In contrast, $\mathrm{WO}_{2.9}$ catalyst exhibits a small $\eta$ value of $-70 \mathrm{mV}$ at the current density of $10 \mathrm{mAcm}^{-2}$, indicating that the tailored structure effectively reduces the energy input for activating the HER. Moreover, for driving a current density of $20 \mathrm{~mA} \mathrm{~cm}^{-2}, \mathrm{WO}_{2.9}$ electrocatalyst only requires an overpotential of $-94 \mathrm{mV}$ (not $i R$ corrected), indicating a performance evidently exceeding most of the reported noblemetal-free HER catalysts (see details in Supplementary Table 2). These results imply that fast electron transfer and HER activation occur on the $\mathrm{WO}_{2.9}$ electrocatalyst (Supplementary Movie 1). Further, the linear portions of the Tafel plots (Fig. 3b) were fit to the Tafel equation $(\eta=b \log j+a$, where $j$ is the current density and $b$ is the Tafel slope $)^{29}$, yielding Tafel slopes of $\sim 30, \sim 50$ and $\sim 120 \mathrm{mV}$ per decade for $\mathrm{Pt} / \mathrm{C}, \mathrm{WO}_{2.9}$ and $\mathrm{WO}_{3}$ samples, respectively. The turnover frequencies (TOFs) were estimated for the $\eta$ value of -100 and $-200 \mathrm{mV}$ using both theoretical and experimental surface areas for the $\mathrm{HER}$ in $0.50 \mathrm{M} \mathrm{H}_{2} \mathrm{SO}_{4}$

Figure 2 | Structure analyses of $\mathbf{W O}_{3}$ and $\mathbf{W O}_{\mathbf{2 . 9}}$ samples. High-angle annular dark-field scanning transmission electron micrograph (HAADFSTEM) images of the samples $\mathrm{WO}_{3}(\mathbf{a}, \mathbf{c})$ and $\mathrm{WO}_{2.9}(\mathbf{b}, \mathbf{d})$. W atoms can be clearly observed, yellow spots in $\mathbf{a}, \mathbf{c}$ and blue spots in $\mathbf{b}, \mathbf{d}$. The bulk structures for (a) $\mathrm{WO}_{3}$, showing continuous lattice fringes (white lines, A for [002] and B for [200]) and (b) $\mathrm{WO}_{2.9}$, revealing a regularly stair-step shape (red lines). The typical surface structures for (c) $\mathrm{WO}_{3}$ and (d) $\mathrm{WO}_{2.9}$. White and red arrows point the surface structure that is similar to bulk structure of $\mathrm{WO}_{3}$ and $\mathrm{WO}_{2.9}$, respectively. Scale bar, $5 \mathrm{~nm}$. (e) X-ray diffraction pattern of sample $\mathrm{WO}_{2.9}$ we synthesized in this work, which is in good agreement with the calculated diffraction pattern of bulk $\mathrm{WO}_{2.9}$ with an extra peak (inverted triangle). theta, diffraction angle. (f) X-ray photoelectron spectroscopy spectra showing the $W 4 f$ core level peak region of the samples $\mathrm{WO}_{2.9}$ and $\mathrm{WO}_{3}$. $(\mathbf{g})$ The normalized $\mathrm{X}$-ray

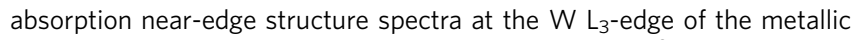
$\mathrm{W}$ powder, $\mathrm{WO}_{3}$ powder and $\mathrm{WO}_{2.9}$ catalyst. (h) The $\mathrm{k}^{3}$-weighted Fourier transform spectra from extended $\mathrm{X}$-ray absorption fine structure. 
a

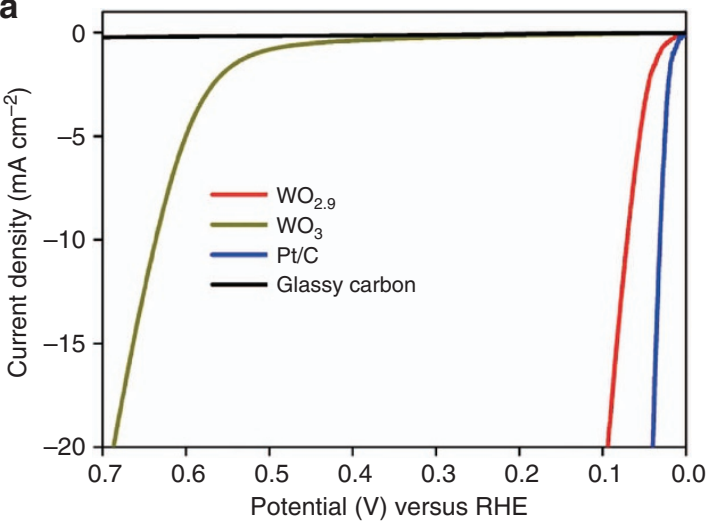

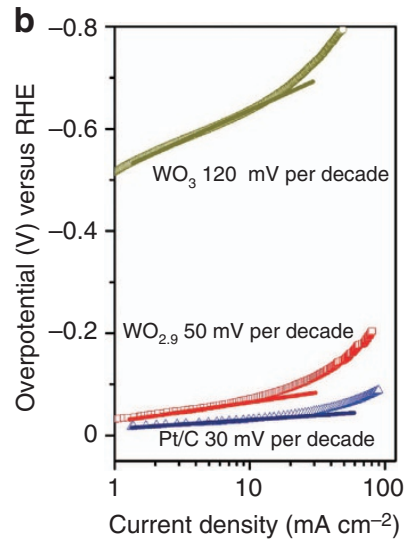

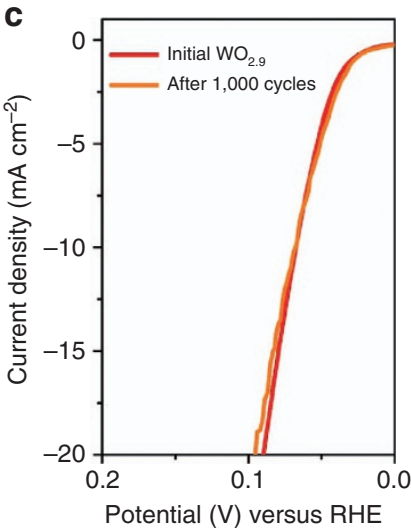

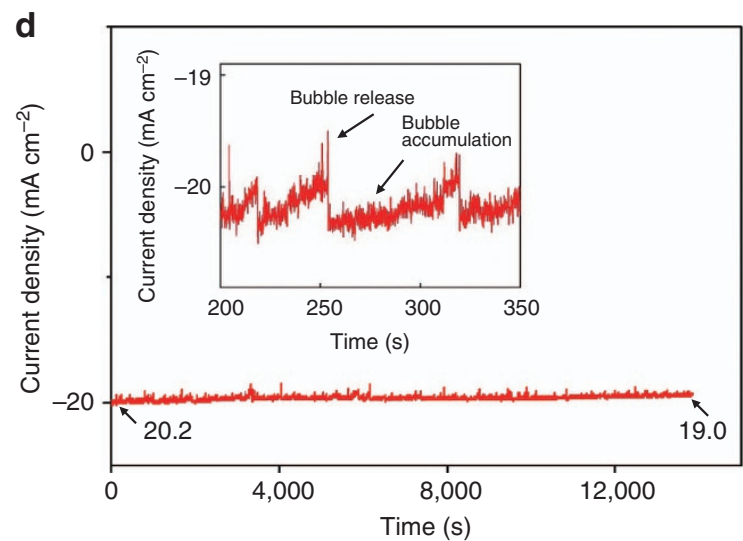

Figure 3 | Hydrogen evolution reaction electrocatalytic properties. (a) Polarization data for the $\mathrm{WO}_{2.9}$ electrodes, along with $\mathrm{WO}$, $\mathrm{Pt} / \mathrm{C}$ and glassy carbon for comparison. (b) Tafel plots of the polarization curves of the $\mathrm{WO}_{2.9}, \mathrm{WO}_{3}$ and $\mathrm{Pt} / \mathrm{C}$. (c) Polarization data for $\mathrm{WO}_{2.9}$ sample sweeps between -0.3 and $+0.1 \mathrm{~V}$ versus RHE, showing negligible current density loss even after 1,000 CV cycles. (d) Time dependence of current density under static overpotential of $-0.1 \mathrm{~V}$. Inset is an enlargement of an area in d. All electrochemical studies were performed in $0.5 \mathrm{M} \mathrm{H}_{2} \mathrm{SO}_{4}$ at room temperature.

\section{Table 1 | Comparison of catalytic parameters of different HER catalysts.}

\begin{tabular}{|c|c|c|c|c|}
\hline Catalyst & $\begin{array}{c}\text { Current } \\
\text { density } \\
\left(j, \mathbf{m A ~ c m}^{-2}\right)\end{array}$ & $\begin{array}{l}\text { Corresponding } \\
\text { overpotential } \\
(\eta, \mathrm{mV})\end{array}$ & $\begin{array}{l}\text { Tafel slope } \\
\text { (mV per } \\
\text { decade) }\end{array}$ & $\begin{array}{c}\text { Exchange } \\
\text { current density } \\
\left(j_{0}, \mathrm{~mA} \mathrm{~cm}^{-2}\right)^{\star}\end{array}$ \\
\hline $\mathrm{WO}_{3}$ & 10 & -637 & 120 & $5.0 \times 10^{-5}$ \\
\hline $\mathrm{WO}_{2.9}$ & 10 & -70 & 50 & 0.40 \\
\hline $\mathrm{Pt} / \mathrm{C}^{\dagger}$ & 10 & -31 & 30 & 0.93 \\
\hline
\end{tabular}

HER, hydrogen evolution reaction; RHE, reversible hydrogen electrode. ${ }^{*}$ jo was calculated from Tafel curves using extrapolation method. $\dagger$ Johnson-Matthey, $20 \mathrm{wt} \% \mathrm{Pt} / \mathrm{XC}-72$.

(Supplementary Note 1$)^{13,30}$. The surface area of the $\mathrm{WO}_{2.9}$ catalyst is about $48.3 \mathrm{~m}^{2} \mathrm{~g}^{-1}$ determined by Brunauer-EmmettTeller study, and the TOFs (per surface $\mathrm{W}$ atom) were calculated to be $8.04 \mathrm{~s}^{-1}$ at $-100 \mathrm{mV}$ and $24.76 \mathrm{~s}^{-1}$ at $-200 \mathrm{mV}$. Theoretical TOF values, estimated geometrically by assuming $100-\mathrm{nm}$ spherical particles of $\mathrm{WO}_{2.9}$, can be $4.64 \mathrm{~s}^{-1}$ at $-100 \mathrm{mV}$ and $14.29 \mathrm{~s}^{-1}$ at $-200 \mathrm{mV}$. In addition, the HER inherent activity of these catalysts was evaluated by the exchange current density $\left(j_{0}\right)$. The $j_{0}$ of $\mathrm{WO}_{2.9}$ catalyst is $0.40 \mathrm{~mA} \mathrm{~cm}-2$ with a surface area of $0.97 \mathrm{~cm}^{2}$ on the working electrode $(0.02 \mathrm{mg}$ loading), which outperforms the value of $5.0 \times 10^{-5} \mathrm{~mA} \mathrm{~cm}^{-2}$ for bulk $\mathrm{WO}_{3}$ (Table 1) and can be superior to those for other reported nonprecious HER catalysts (Supplementary Table 2). The high electrode kinetic metrics (including the overpotential of $-70 \mathrm{mV}$ at the current density of $10 \mathrm{~mA} \mathrm{~cm}^{-2}$ and the Tafel slope of $50 \mathrm{mV}$ per decade) and large $j_{0}$ (only half lower than the value of $0.93 \mathrm{~mA} \mathrm{~cm}^{-2}$ for $\mathrm{Pt}$ ) highlight the exceptional $\mathrm{H}_{2}$ evolving efficiency of the $\mathrm{WO}_{2.9}$ catalyst.

Cyclic voltammetry (CV) was swept between -0.3 and $+0.1 \mathrm{~V}$ (versus the reversible hydrogen electrode potential, $\mathrm{RHE})$ were applied to the $\mathrm{WO}_{2.9}$-decorated working electrodes (Fig. 3c). After 1,000 CV sweeps, the overpotential required to achieve current densities of $10 \mathrm{~mA} \mathrm{~cm}^{-2}$ shows negligible change (from 70 to $71 \mathrm{mV}$ ), which remains higher than those of the benchmark catalysts (Supplementary Table 2). Moreover, we swept the CV towards positive potential up to $+1.0 \mathrm{~V}$ (versus RHE) with scan rate of $0.02 \mathrm{~V} \mathrm{~s}^{-1}$ for 50 times (Supplementary Fig. 8). However, the $\mathrm{WO}_{2.9}$ catalyst shows an undesirable degradation of HER performance, indicating that it could hardly withstand excursions to positive potentials. Continuous HER at a static overpotential was also conducted. As shown in Fig. 3d, when an overpotential of $-0.1 \mathrm{~V}$ was applied, a continuous HER process occurred to generate molecular $\mathrm{H}_{2}$. The as-measured time-dependent curve is in typical serrate shape, which could be attributed to the alternate processes of bubble accumulation and bubble release (inset in Fig. 3d). The amount of the decay of the $\mathrm{WO}_{2.9}$ catalyst is about $5.9 \%$ current loss after $14,000 \mathrm{~s}$, which might be owing to the partial detachment of the catalyst caused by the continues bubbles releasing or the remaining of $\mathrm{H}_{2}$ bubbles on the surface of the electrode that hindered the reaction. The current density levelled out at an average of $19.6 \mathrm{~mA} \mathrm{~cm}^{-2}$ with the $\mathrm{WO}_{2.9}$ working electrode $\left(0.07 \mathrm{~cm}^{2}\right.$ surface area, $0.285 \mathrm{mg} \mathrm{cm}^{-2}$ loading), resulting in passage of $19.2 \mathrm{C}$ of charge. On the other hand, control experiments run under identical conditions, but with the $\mathrm{WO}_{3}$ sample and without the catalyst, both showed no current. We further established the HER scale 
after the static overpotential test of the $\mathrm{WO}_{2.9}$ catalyst via a gas chromatograph (GC-2014C) with the argon as carrier gas. The total $\mathrm{H}_{2}$ amount is about $95 \mu \mathrm{mol}$, which is consistent with the theoretical value of $99.5 \mu \mathrm{mol}$ by assuming that every electron is used for the reduction of protons.

In addition, we performed the XRD and XPS techniques to determine the structure of the $\mathrm{WO}_{2.9}$ catalyst after these electrocatalytic tests. As shown in Supplementary Fig. 9, diffraction peaks in pattern of sample $\mathrm{WO}_{2.9}$ remains at the similar intensity and position compared to those in Fig. 2e, revealing the unchanged local structure of $\mathrm{WO}_{2.9}$ catalyst. Moreover, the deconvoluted $\mathrm{W} 4 f$ doublet peaks of the catalyst after the tests exhibit negligible difference. The dispersion of $\mathrm{W}^{5+}$ in both samples, which can be evaluated by the relative XPS intensity ratio of $\mathrm{W}^{5+}$ atom to $\mathrm{W}^{6+}$ atom, shows negligible change, remaining as 0.182 for the before and after samples. Specifically, we also detected the Pt $4 f$ core level peak region to check for the possible impurities, and the existence of Pt can be thus safely ruled out. All results suggest that the origin of the excellent HER capacity could be attributed to the tailored electronic structure of $\mathrm{WO}_{2.9}$ catalyst by means of local atomic structure modulations.

Density functional theory studies. On the basis of the above experimental investigations, we thus systematically examined the binding ability of their respective most stable surface, that is, $\mathrm{WO}_{2.9}(010)$ and $\mathrm{WO}_{3}(001)$ by virtue of extensive first-principle density functional theory (DFT) calculations (see details in Fig. 4,
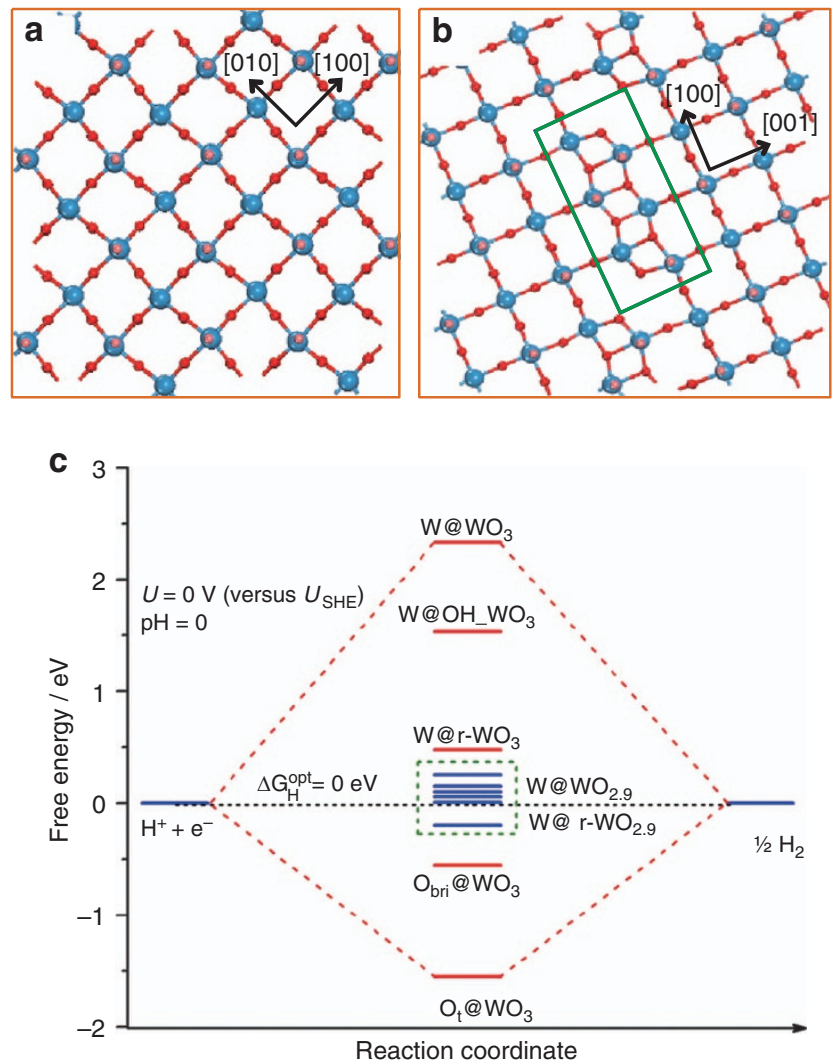

Figure 4 | Density functional theory calculations. Top views of the optimized configuration of monoclinic $\mathrm{WO}_{3}(001)(\mathbf{a})$ and $\mathrm{WO}_{2.9}(010)$ surface (b), in which the box indicates the new characteristic configuration possessed by $\mathrm{WO}_{2.9}$ relative to $\mathrm{WO}_{3}$. Blue balls represent $\mathrm{W}$ atom, red for $\mathrm{O}$ and pink for the surface terminal $\mathrm{O}$. This notation is used throughout this work. (c) Calculated free energy diagram of HER at the equilibrium potential $\left(U=U_{\text {SHE }}\right)$ for a series of active sites on $\mathrm{WO}_{3}(001)$ and $\mathrm{WO}_{2.9}(010)$.
Supplementary Figs 10-13 and Supplementary Note 2). The calculated parameters (Supplementary Table 3) show that the adsorption energy on $\mathrm{WO}_{2.9}(010)$ is largely enhanced relative to that on $\mathrm{WO}_{3}(001)$. For example, the adsorption energy can be $-0.19 \mathrm{eV}$ on $\mathrm{WO}_{2.9}(010)$, and accordingly, the free energy change of the discharge step $\left(\mathrm{H}^{+}+\mathrm{e}^{-} \rightarrow \mathrm{H}^{\star}\right)$ for HER at the standard condition $\left(U=0 \mathrm{~V}\right.$ versus $\left.U_{\mathrm{SHE}}, \mathrm{pH}=0\right)$ can be calculated to be $0.01 \mathrm{eV}$, fulfilling the $\Delta G_{\mathrm{H}}=0 \mathrm{eV}$ requirement, and thus its high catalytic activity could be expected. Moreover, the formed terminal $\mathrm{OH}$ could further adsorb $\mathrm{H}$ and form $\mathrm{H}_{2} \mathrm{O}$, resulting in the possible reduction. We thus considered the surface reduction by removing all the terminal $\mathrm{O}$ from the $p(1 \times 1) \quad \mathrm{WO}_{2.9}(010)$ slab, corresponding to a $\mathrm{W} / \mathrm{O}$ ratio of $\mathrm{W}_{60} \mathrm{O}_{154}$, whose adsorption energy can be further improved by the order of only $\sim 0.30 \mathrm{eV}$ compared with the clean $\mathrm{WO}_{2.9}(010)$ surface (Supplementary Table 4). From Fig. 4c, the activity can remain at a high level, despite being a little lower to some extent relative to clean $\mathrm{WO}_{2.9}(010)$. Therefore, it could be rationalized that $\mathrm{WO}_{2.9}$ exhibits a high and stable activity. We further performed a brief electronic analysis to provide insight into the enhanced $\mathrm{H}$ adsorption strength of $\mathrm{WO}_{2.9}(010)$. One can see that the highest occupied $d$-orbital of surface $\mathrm{W}_{5 \mathrm{c}}$ largely affects the binding ability toward $\mathrm{H}$ atom (Supplementary Figs 14-16), and the appearance of $d$-band around the Fermi level for $\mathrm{WO}_{2.9}(010)$ would be an important factor for the strengthened binding ability compared with $\mathrm{WO}_{3}$. In addition, the calculated work function suggests that $\mathrm{WO}_{2.9}$ has a higher Fermi level than $\mathrm{WO}_{3}$ by $0.70 \mathrm{eV}$, which may facilitate the reduction process to occur kinetically.

Stability of $\mathbf{W O}_{2.9}$ electrocatalyst. To further probe the stability of the $\mathrm{WO}_{2.9}$ catalyst during electrocatalytic hydrogen evolution in $0.5 \mathrm{M} \mathrm{H}_{2} \mathrm{SO}_{4}$, the $\mathrm{CV}$ of $\mathrm{WO}_{2.9}$ catalyst was swept between -0.3 and $+0.1 \mathrm{~V}$ for 10,000 times (Supplementary Fig. 17). As with many metal oxides, $\mathrm{WO}_{2.9}$ nanoparticles also suffer from the undesired structure change in acidic water for a long time; they are slightly soluble after these additional accelerated degradation studies, which results in the degradation of electrocatalytic activity. The overpotential increased from -94 to $-162 \mathrm{mV}$ at the current density of $20 \mathrm{~mA} \mathrm{~cm}^{-2}$ after 10,000 CV sweeps. XRD pattern in Supplementary Fig. 18 reveals partial formation of $\mathrm{WO}_{2.8}$ phase in catalyst, and the XPS spectrum also shows an enhancement of the $\mathrm{W}^{5+}$ doublet peaks in the spectrum from those of fresh $\mathrm{WO}_{2.9}$ sample (Supplementary Fig. 19), indicating the high oxygen vacancies of the atomic structure in acidic water for the rigorous tests. It should be noted, however, that the $\mathrm{WO}_{2.9}$ catalyst is still much more thermodynamically stable in acidic water than most metal oxides. Further investigation is needed to obtain a clear picture of the exact microscopic changes to their surface chemistry and lattice structure. We believe that, with further research, the deactivation may be reduced or eliminated, for example, by integrating $\mathrm{WO}_{2.9}$ nanoparticles with a graphene shell or other nanostructures ${ }^{31-33}$.

\section{Discussion}

The $\mathrm{WO}_{2.9}$ electrocatalyst prepared in this work exhibits excellent HER activity with a very low cathodic overpotential of $-70 \mathrm{mV}$ at the current density of $10 \mathrm{~mA} \mathrm{~cm}^{-2}$ and a small Tafel slope of about $50 \mathrm{mV}$ per decade. By modulating the local atomic structure of $\mathrm{WO}_{3}$ at the atomic scale, an extended and ordered defect structure (Magnéli phase) is formed, resulting in preferentially exposed $\mathrm{W}$ sites with modified electronic structure that show a greatly enhanced catalytic activity for hydrogen evolution. We anticipate the transition metal oxide materials with suitable metal hydrogen binding energy may also hold the 
promises to compete against the best precious metal catalysts available for HER, compared with the well-studied carbides, nitrides, phosphides and sulfides.

\section{Methods}

Synthesis of catalyst. In the preparation of the material, a two-step synthesis process was involved. First, $1 \mathrm{~g}$ of commercial $\mathrm{WO}_{3}$ (of analytically pure grade, $99.9 \%$, Sinopharm) was carefully ground, which was carried out in a ball mill with the wet grinding method (ethanol, $24 \mathrm{~h}$ under rotation speed of 300 r.p.m.). Then, we prepared the thermally treated samples through annealing ground $\mathrm{WO}_{3}$ in hydrogen atmosphere ( 1 bar, $10 \% \mathrm{H}_{2}, 90 \%$ Ar, 100 s.c.c.m. flow) in a tube furnace at $500{ }^{\circ} \mathrm{C}$ for $60 \mathrm{~min}$. The resulting powder can be collected after the tube furnace cooling down to room temperature.

Electrochemical measurements. Four microgram of catalyst and $80 \mu \mathrm{l}$ of $5 \mathrm{wt} \%$ Nafion solution (Sigma-Aldrich) were dispersed in $1 \mathrm{ml}$ of $4: 1 \mathrm{v} / \mathrm{v}$ water/ethanol by at least 30-min sonication to form a homogeneous ink. Then, $5 \mu \mathrm{l}$ of the catalyst ink (containing $20 \mu \mathrm{g}$ of catalyst) was loaded onto a GCE of $3 \mathrm{~mm}$ in diameter (loading $0.285 \mathrm{mg} \mathrm{cm}^{-2}$ ). The area of coated electrodes may exceed that of the glassy carbon disc, but we calculate all the current densities using the geometric value. The $\mathrm{WO}_{2.9}$ modified GCE was left to dry at $40^{\circ} \mathrm{C}$. For comparison, GCEs were also modified with commercial $\mathrm{WO}_{3}$ from Sinopharm (99.9\%) and $\mathrm{Pt} / \mathrm{C}(5 \%)$ from Alfa Aesar.

All electrochemical studies were performed using a CHI 660 potentiostat (CH Instruments, China) in a three-electrode setup with a modified glassy carbon working electrode, an $\mathrm{Ag} / \mathrm{AgCl} / \mathrm{KCl}(3.5 \mathrm{M})$ electrode as a reference, a graphite rod (spectral purity, 3-mm diameter) as a counter electrode and deaerated with hydrogen before use. The electrocatalytic activity of $\mathrm{WO}_{2.9}$ towards HER was examined by polarization curves using linear sweep voltammetry at a scan rate of $5 \mathrm{mV} \mathrm{s}^{-1}$ in $0.5 \mathrm{M} \mathrm{H}_{2} \mathrm{SO}_{4}$ at room temperature. All of the potentials in this work were calibrated to a RHE. The amount of evolved $\mathrm{H}_{2}$ was monitored by a gas chromatograph (GC-2014C) with argon as carrier gas.

Catalysts characterization. The crystal structure was determined using XRD (D/MAX $2550 \mathrm{VB} / \mathrm{PC}$ ) and Raman spectroscopy (Renishaw, inVia + Reflex). The structure of the catalysts was examined by SEM (S-3400N) and TEM (TECNAI F-30, $300 \mathrm{kV}$ ). Further, the chemical states of the elements in catalysts were studied by XPS (ESCALAB 250Xi), and the binding energy of the $\mathrm{C} 1 \mathrm{~s}$ peak at $283.9 \mathrm{eV}$ was taken as an internal reference. $\mathrm{W} \mathrm{L}_{3}$-edge absorption spectra (extended XAFS) were performed on the 1W1B beamline of the Beijing Synchrotron Radiation Facility, China, operated at $\sim 200 \mathrm{~mA}$ and $\sim 2.5 \mathrm{GeV}$. W foil and $\mathrm{WO}_{3}$ powder were used as the reference samples. All samples were measured in the transmission mode. Brunauer-Emmett-Teller surface area measurement was performed at $77 \mathrm{~K}$ on a Micromeritics ASAS 2460 adsorption analyzer in $\mathrm{N}_{2}$ adsorption mode.

Theoretical calculation. All the spin-polarized calculations were performed with Perdew-Burke-Ernzerhof functional within the generalized gradient approximation using the Vienna Ab-initio Simulation Package (VASP) code, unless otherwise specified. The project-augmented wave method was used to represent the corevalence electron interaction. The valence electronic states were expanded in plane wave basis sets with energy cutoff at $450 \mathrm{eV}$. The occupancy of the one-electron states was calculated using the Gaussian smearing $($ SIGMA $=0.05 \mathrm{eV})$. The ionic degrees of freedom were relaxed using the Broyden-Fletcher-Goldfarb-Shanno (BFGS) minimization scheme until the Hellman-Feynman forces on each ion were $<0.05 \mathrm{eV}^{-1}$. The transition states were searched using a constrained optimization scheme, and were verified when (i) all forces on atoms vanish; and (ii) the total energy is a maximum along the reaction coordination but a minimum with respect to the rest of the degrees of freedom.

To model the monoclinic $\mathrm{WO}_{3}(001)$ surface, a nine-layer $c(\sqrt{ } 2 \times \sqrt{ } 2) \mathrm{R} 45^{\circ}$ slab $\left(10.772 \times 10.805 \AA^{2}\right)$ with a vacuum layer of $15 \AA$ was adopted, corresponding to $\left(\mathrm{WO}_{3}\right)_{32}$ (128 atoms). For $\mathrm{WO}_{29}(010)$ surface, an enough large seven-layer $p(1 \times 1)$ slab $\left(23.839 \times 12.202 \AA^{2}\right)$ was used as the model. Because of the large size of the $\mathrm{WO}_{2.9}(010)$ supercell, $k$-point sampling was restricted to the $\Gamma$ point only. It is worth noting that, all the atomic layers in the optimization of $\mathrm{WO}_{29}(010)$ were allowed to relax and the surfaces were constructed based on the pre-optimized bulk unit cell (see the optimized lattice constants of the monoclinic $\mathrm{WO}_{3}$ and $\mathrm{WO}_{2.9}$ in Supplementary Table 5)

Free energy calculation method. To obtain the free energy of the each elementary step, when involving $\mathrm{H}^{+}+\mathrm{e}^{-}$, the standard hydrogen electrode (SHE) was used as the reference in standard Gibbs free energy calculation of HER. As derived in our previous work, Gibbs free energy change $(\Delta G)$ of each elementary step can be calculated as follows:

$$
\begin{gathered}
\Delta G_{1}=E_{\mathrm{ad}}^{\mathrm{H}}+1 / 2 T \Delta S+\mathrm{e} U-k \operatorname{T} \ln C_{\mathrm{H}^{+}} \\
\Delta G_{2}=-2 E_{\mathrm{ad}}^{\mathrm{H}}-T \Delta S+k \operatorname{T} \ln P_{\mathrm{H}_{2}}
\end{gathered}
$$

in which $U$ is the electronic voltage versus SHE, while $P_{\mathrm{H}_{2}}$ and $C_{\mathrm{H}^{+}}$are the relative partial pressure of $\mathrm{H}_{2}$ and the relative concentration of $\mathrm{H}^{+}$in the aqueous solution, respectively. At the standard condition, there are approximately $\Delta G_{1}=E_{\mathrm{ad}}^{\mathrm{H}}+0.20 \mathrm{eV}$. The adsorption energy $\left(E_{\mathrm{ad}}^{\mathrm{H}}\right)$ for hydrogen was obtained from the DFT calculation at $0 \mathrm{~K}$ relative to gas phase $\mathrm{H}_{2}$ molecule, which is defined as equation (3).

$$
E_{\mathrm{ad}}^{\mathrm{H}}=E_{\mathrm{H} / \mathrm{sur}}-E_{\mathrm{sur}}-1 / 2 E_{\mathrm{H}_{2}}
$$

where $E_{\mathrm{H} / \mathrm{sur}}$ and $E_{\mathrm{sur}}$ are the energy of the surface slab with and without atomic $\mathrm{H}$ adsorption, and $E_{\mathrm{H}_{2}}$ is the total energy of the $\mathrm{H}_{2}$ molecule in the gas phase. The more negative $E_{\mathrm{ad}}^{\mathrm{H}}$ is, the more strongly the species $\mathrm{H}$ binds on surface.

\section{References}

1. Dresselhaus, M. S. \& Thomas, I. L. Alternative energy technologies. Nature 414, 332-337 (2001).

2. Subbaraman, R. et al. Enhancing hydrogen evolution activity in water splitting by tailoring $\mathrm{Li}^{+}-\mathrm{Ni}(\mathrm{OH})_{2}$-Pt interfaces. Science 334, 1256-1260 (2011).

3. Chen, X., Liu, L., Yu, P. Y. \& Mao, S. S. Increasing solar absorption for photocatalysis with black hydrogenated titanium dioxide nanocrystals. Science 331, 746-750 (2011).

4. Gao, M.-R. et al. An efficient molybdenum disulfide/cobalt diselenide hybrid catalyst for electrochemical hydrogen generation. Nat. Commun. 6, 5982 (2015).

5. Zheng, Y. et al. Hydrogen evolution by a metal-free electrocatalyst. Nat. Commun. 5, 3783 (2014).

6. Evans, D. J. \& Pickett, C. J. Chemistry and the hydrogenases. Chem. Soc. Rev. 32, 268-275 (2003).

7. Dubois, M. R. \& Dubois, D. L. Development of molecular electrocatalysts for $\mathrm{CO}_{2}$ reduction and $\mathrm{H}_{2}$ production/oxidation. Acc. Chem. Res. 42, 1974-1982 (2009).

8. Inglis, J. L., MacLean, B. J., Pryce, M. T. \& Vos, J. G. Electrocatalytic pathways towards sustainable fuel production from water and $\mathrm{CO}_{2}$. Coordin. Chem. Rev. 256, 2571-2600 (2012).

9. Yin, H. et al. Ultrathin platinum nanowires grown on single-layered nicke hydroxide with high hydrogen evolution activity. Nat. Commun. 6, 6430 (2015).

10. Dempsey, J. L., Brunschwig, B. S., Winkler, J. R. \& Gray, H. B. Hydrogen evolution catalyzed by cobaloximes. Acc. Chem. Res. 42, 1995-2004 (2009)

11. Chen, W.-F. et al. Biomass-derived electrocatalytic composites for hydrogen evolution. Energy Environ. Sci. 6, 1818-1826 (2013).

12. Cao, B., Veith, G. M., Neuefeind, J. C., Adzic, R. R. \& Khalifah, P. G. Mixed close-packed cobalt molybdenum nitrides as non-noble metal electrocatalysts for the hydrogen evolution reaction. J. Am. Chem. Soc. 135, 19186-19192 (2013).

13. Popczun, E. J. et al. Nanostructured nickel phosphide as an electrocatalyst for the hydrogen evolution reaction. J. Am. Chem. Soc. 135, 9267-9270 (2013).

14. Kibsgaard, J., Chen, Z., Reinecke, B. N. \& Jaramillo, T. F. Engineering the surface structure of $\mathrm{MoS}_{2}$ to preferentially expose active edge sites for electrocatalysis. Nat. Mater. 11, 963-969 (2012).

15. Liu, Y., Luo, C. \& Liu, H. Tungsten trioxide promoted selective conversion of cellulose into propylene glycol and ethylene glycol on a ruthenium catalyst. Angew. Chem. Int. Ed. Engl. 51, 3249-3253 (2012).

16. Shi, X. et al. Efficient photoelectrochemical hydrogen production from bismuth vanadate-decorated tungsten trioxide helix nanostructures. Nat. Commun. 5, 4775 (2014).

17. Lorenz, M., Wenckstern, H. \& Grundmann, M. Tungsten oxide as a gate dielectric for highly transparent and temperature-stable zinc-oxide-based thin-film transistors. Adv. Mater. 23, 5383-5386 (2011).

18. Devan, R. S., Patil, R. A., Lin, J.-H. \& Ma, Y.-R. One-dimensional metal-oxide nanostructures: recent developments in synthesis, characterization, and applications. Adv. Funct. Mater. 22, 3326-3370 (2012).

19. Maiyalagan, T. \& Viswanathan, B. Catalytic activity of platinum/tungsten oxide nanorod electrodes towards electro-oxidation of methanol. J. Power Sources 175, 789-793 (2008)

20. Wickman, B., Wesselmark, M., Lagergren, C. \& Lindbergh, G. Tungsten oxide in polymer electrolyte fuel cell electrodes-a thin-film model electrode study. Electrochim. Acta 56, 9496-9503 (2011).

21. Ganesan, R. \& Gedanken, A. Synthesis of $\mathrm{WO}_{3}$ nanoparticles using a biopolymer as a template for electrocatalytic hydrogen evolution. Nanotechnology 19, 025702 (2008).

22. Greeley, J., Jaramillo, T. F., Bonde, J., Chorkendorff, I. \& Nørskov, J. K. Computational high-throughput screening of electrocatalytic materials for hydrogen evolution. Nat. Mater. 5, 909-913 (2006).

23. Chen, C. et al. Highly crystalline multimetallic nanoframes with three-dimensional electrocatalytic surfaces. Science 343, 1339-1343 (2014).

24. Kieslich, G. et al. Enhanced thermoelectric properties of the n-type Magnéli phase $\mathrm{WO}_{2.90}$ : reduced thermal conductivity through microstructure engineering. J. Mater. Chem. A 2, 13492-13497 (2014) 
25. Zhang, W. F., He, Y. L., Zhang, M. S., Yin, Z. \& Chen, Q. Raman scattering study on anatase $\mathrm{TiO}_{2}$ nanocrystals. J. Phys. D: Appl. Phys. 33, 912-916 (2000).

26. Wang, G. et al. Hydrogen-treated $\mathrm{WO}_{3}$ nanoflakes show enhanced photostability. Energy Environ. Sci. 5, 6180-6187 (2012).

27. Xie, F. Y. et al. XPS studies on surface reduction of tungsten oxide nanowire film by $\mathrm{Ar}^{+}$bombardment. J. Electron. Spectrosc. Relat. Phenom. 185, 112-118 (2012).

28. Zhuiykov, S., Kats, E., Carey, B. \& Balendhran, S. Proton intercalated two-dimensional $\mathrm{WO}_{3}$ nano-flakes with enhanced charge-carrier mobility at room temperature. Nanoscale 6, 15029-15036 (2014).

29. Vrubel, H. \& Hu, X. Molybdenum boride and carbide catalyze hydrogen evolution in both acidic and basic solutions. Angew. Chem. Int. Ed. Engl. 51, 12703-12706 (2012)

30. Song, F. \& Hu, X. Ultrathin cobalt - manganese layered double hydroxide is an efficient oxygen evolution catalyst. J. Am. Chem. Soc. 136, 16481-16484 (2014).

31. Xu, Y.-F., Gao, M.-R., Zheng, Y.-R., Jiang, J. \& Yu, S.-H. Nickel/nickel(II) oxide nanoparticles anchored onto cobalt(IV) diselenide nanobelts for the electrochemical production of hydrogen. Angew. Chem. Int. Ed. Engl. 52, 8546-8550 (2013).

32. Deng, J. et al. Highly active and durable non-precious-metal catalysts encapsulated in carbon nanotubes for hydrogen evolution reaction. Energy Environ. Sci. 7, 1919-1923 (2014).

33. Deng, J., Ren, P., Deng, D. \& Bao, X. Enhanced electron penetration through an ultrathin graphene layer for highly efficient catalysis of the hydrogen evolution reaction. Angew. Chem. Int. Ed. Engl. 54, 2100-2104 (2015).

\section{Acknowledgements}

This work was financially supported by the Science Fund for Creative Research Groups (21421004), National Natural Science Foundation of China (21373083 and 21303052), SRF for ROCS, SEM, SRFDP, Programme for Professor of Special Appointment (Eastern Scholar) at Shanghai Institutions of Higher Learning, Program of Shanghai Subject Chief Scientist (15XD1501300), and Fundamental Research Funds for the Central Universities
(WD1313009, 222201314035), the Commission of Science and Technology of Shanghai Municipality (12ZR1442600).

\section{Author contributions}

H.G.Y. conceived the project and contributed to the design of the experiments and analysis of the data. Y.H.L. performed the catalyst preparation, characterizations and wrote the paper. Z.Z.Y. and L.G. conducted the STEM examination and contributed to writing the STEM section. L.F.P., P.F.L. and H.J.Z. collected the electrochemical data. L.R.Z. carried out measurements and data analyses of XAFS. H.F.W. and P.H. conducted DFT calculations and wrote part of the paper (calculations). All the authors discussed the results and commented on the manuscript.

\section{Additional information}

Supplementary Information accompanies this paper at http://www.nature.com/ naturecommunications

Competing financial interests: The authors declare no competing financial interests.

Reprints and permission information is available online at http://npg.nature.com/ reprintsandpermissions/

How to cite this article: Li, Y. H. et al. Local atomic structure modulations activate meta oxide as electrocatalyst for hydrogen evolution in acidic water. Nat. Commun. 6:8064 doi: $10.1038 /$ ncomms9064 (2015).

(c) (i) This work is licensed under a Creative Commons Attribution 4.0 International License. The images or other third party material in this article are included in the article's Creative Commons license, unless indicated otherwise in the credit line; if the material is not included under the Creative Commons license, users will need to obtain permission from the license holder to reproduce the material. To view a copy of this license, visit http://creativecommons.org/licenses/by/4.0/ 